\title{
PERANCANGAN MONITORING PRESTASI AKADEMIK DAN AKTIVITAS SISWA MENGGUNAKAN PENDEKATAN KEY PERFORMANCE INDICATOR (STUDI KASUS SMA N 1 KALIREJO)
}

\author{
Suaidah $^{1)}$, Irvan Sidni ${ }^{\text {) }}$ \\ ${ }^{1), 2)}$ Sistem Informasi, Universitas Teknokrat Indonesia \\ Jl. H.ZA Pagaralam, No 9-11, Labuhanratu, Bandarlampung \\ Email : suaidah@teknokrat.ac.id ${ }^{1)}$,irvansidni1117@gmail.com ${ }^{2)}$
}

\begin{abstract}
Abstrak
Sekolah saat ini adalah prioritas utama bagi pihak orang tua agar anak-anaknya dapat menuntut ilmu dan menjadi anak yang cerdas, pintar dan berbakti kepada orang tua dan dapat membanggakan nama baik keluarga maupun bangsa, namun saat ini kondisi pendidikan yang ada di Indonesia khususnya di tempat pedalaman atau tempat-tempat yang jarang dapat perhatian oleh pemerintah mengalami kemunduran bagi sarana dan prasarana dan kurangnya pemanfaatan teknologi sekarang ini, sehingga harus dilakukan perubahan agar dapat memanfaaatkannya dengan baik. Metode yang digunakan dalam pemecahan masalah pada penelitian ini adalah metode pengembangan sistem menggunakan metode Waterfall serta perancangan sistem menggunakan UML (Unified Modelling Language): Usecase Diagram, Activity Diagram, Class Diagram, dan Sequence Diagram, sedangkan untuk bahasa pemrograman menggunakan PHP, aplikasinya dreamweaver dan MySQL sebagai database Monitoring. Perancangan Monitoring prestasi akademik dan aktifitas siswa berbasis web dapat memudahkan guru, orang tua dalam mengetahui informasi nilai si anak dengan cara membuka website Perancangan Monitoring Prestasi Akademik dan Aktifitas Siswa.
\end{abstract}

Kata Kunci : Monitoring Web, UML, Metode Waterfall

\section{Pendahuluan}

Poerwanto (2007) memberikan pengertian prestasi belajar yaitu "hasil yang dicapai oleh seseorang dalam usaha belajar sebagaimana yang dinyatakan dalam raport" Selanjutnya Winkel (1997) mengatakan bahwa "prestasi belajar adalah suatu bukti keberhasilan belajar atau kemampuan seseorang siswa dalam melakukan kegiatan belajar sesuai dengan bobot yang dicapainya" Sedangkan menurut Nasution, S (1987) prestasi belajar adalah " kesempurnaan yang dicapai seseorang dalam berfikir, merasa dan berbuat, prestasi belajar dikatakan sempurna apabila memenuhi tiga aspek yakni: kognitif, afektif dan psikomotor, sebaliknya dikatakan prestasi kurang memuaskan jika seseorang belum mampumemenuhi target dalam ketiga kriteria tersebut". Berdasarkan pengertian diatas, maka dapat dijelaskan bahwa prestasi belajar merupakan tingkat kemanusiaan yang dimiliki siswa dalam menerima, menolak dan menilai informasiinformasi yang diperoleh dalam proses belajar mengajar. Prestasi belajar seseorang sesuai dengan tingkat keberhasilan sesuatu dalam mempelajari materi pelajaran yang dinyatakan dalam bentuk nilai atau raport setiap bidang studi setelah mengalami proses belajar mengajar. Prestasi belajar siswa dapat diketahui setelah diadakan evaluasi. Hasil dari evaluasi dapat memperlihatkan tentang tinggi atau rendahnya prestasi belajar siswa.

Monitoring membantu mengingatkan ketika terjadi sesuatu yang salah dan membantu agar pekerjaan tetap pada jalurnya, monitoring bertujuan meningkatkan efektifitas dan efisiensi dari sebuah kegiatan, dan didasarkan pada sasaran dan rencana kegiatan yang sudah ditentukan, monitoring memungkinkan kita untuk untuk menentukan apakah sumber daya kita telah mencukupi dan telah digunakan dengan baik dan menjadi dasar yang berguna untuk evaluasi selanjutnya.

Banyak orang tua yang beranggapan bahwa anak mereka setelah diserahkan kepada guru disekolah maka lepaslah hak dan kewajibannya untuk memberikan pendidikan kepada mereka, Semua tanggung jawabnya telah beralih kepada guru di seklah, apakah menjadi pandai atau bodoh anak tersebut, akan menjadi nakal atau berbudi pekerti yang baik dan luhur, maka itu adalah urusan guru di sekolah (Syah, 2012), namun selama ini pengawasan terhadap siswa sebagian besar hanya dilakukan oleh pihak sekolah terlebih lagi tingkat kesibukan yang tinggi, orang tua minim melakukan memonitor terhadap perkembangan anakanaknya di sekolah. Dari latar belakang dan pemaparan diatas tentang sistem monitoring saya menyimpulkan perkiraan hasil dari penelitian ini adalah dengan adanya system monitoring yang dibuat diharapkan mempermudah orang tua untuk mengawasi anaknya sehingga prestasi anak tersebut dapat terkontrol dengan baik.

\section{Pembahasan}

Monitoring adalah Pengumpulan informasi secara terus menerus dan teratur yang akan membantu menjawab pertanyaan mengenai suatu kegiatan. Monitoring membantu mengingatkan ketika terjadi sesuatu yang 
salah dan membantu agar pekerjaan tetap pada jalurnya.

Key Performance Indicator Adalah sekumpulan pengukuran yang diciptakan terfokus kepada aspek kinerja organisasi yang paling kritikal untuk kesuksesan organisasi pada kondisi sekarang dan di masa datang. Key performance indicator adalah sebuah pengukuran yang menilai bagaimana sebuah organisasi mengeksekusi visi strategisnya. Visi strategis yang dimaksud merujuk kepada bagaimana strategi organisasi secara interaktif terintegrasi dalam strategi organisasi secara menyeluruh.

\section{Metode penelitian}

Metode penelitian yang digunakan dalam perancangan monitoring prestasi akademik dan aktivitas siswa menggunakan pendekatan key performance indicator dapat dilihat pada Error! Reference source not

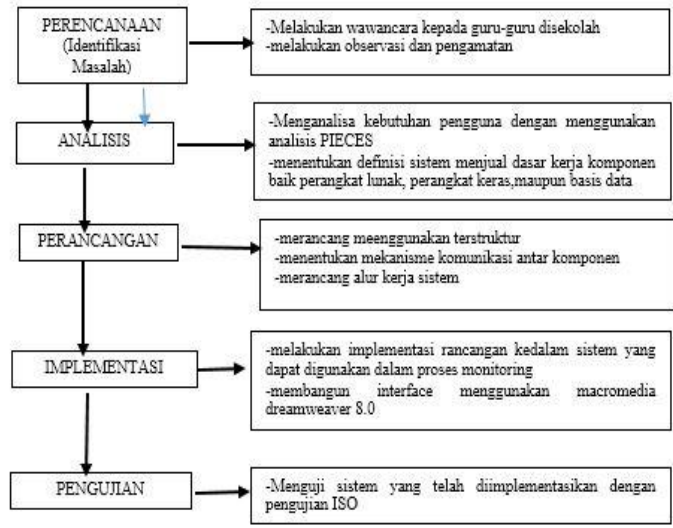

found.

Error! Reference source not found.. Kerangka Penelitian

\subsection{Metode Pengumpulan Data}

Penelitian ini dilakukan dengan menggunakan bahan berupa teknik pengumpulan data Pengamatan (Observation Partisipasif) dan Wawancara (Interview)

\subsection{Analisis dan Kebutuhan Perangkat Keras}

Analisis perangkat keras dimaksud kan untuk mengetahui spesifikasi perangkat keras yang sedang digunakan oleh pengguna adalah Processor dengan kecepatan $1.80 \mathrm{GHz}+$ Motherboard, VGA Card 128 MB, Memory 2048 MB/ 2 GB, Hard disk space 500 GB, Monitor, Keyboard, Printer.

\subsection{Perancangan}

Menurut Seorang ahli perancangan adalah memuat sejumlah prinsip-prinsip, konsep-konsep, dan praktikpraktik yang memampukan kita untuk mengembangkan sistem/perangkat lunak atau produk yang berkualitas tinggi (Presman,2012).

\section{Use Case Diagram}

Use case diagram merupakan use case yang menjelaskan beberapa proses yang ada pada halaman sistem. Admin berfungsi untuk mengelola data siswa,data guru, mengolah data kelas, memperbarui informasi, membuat laporan. Untuk orang tua dapat mengakses halaman utama, form lihat nilai, form informasi sekolah. Berikut use case Sistem Informasi Monitoring prestasi akademik dan aktifitas siswa pada SMA N 1 Kalirejo dapat dilihat pada Error! Reference source not found. 2 .

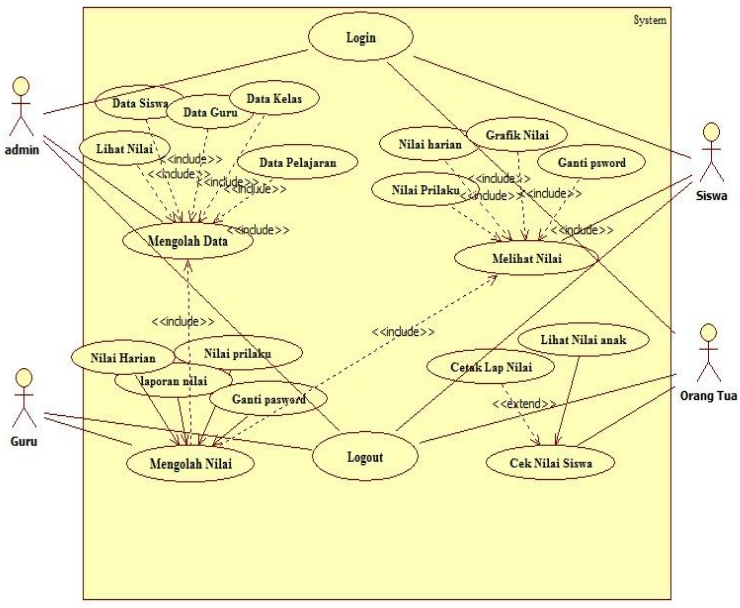

Gambar 2. Use case Diagram

\section{Activity Diagram}

\section{a) Activity Diagram Admin olah data admin}

Berikut adalah aktivitas admin untuk mengolah data admin yang bisa mengubah data menghapus dan sebagainya.Admin berperan penting dalam system ini karena semua data- data siswa dan guru diatur oleh pihak admin dapat dilihat pada Error! Reference source not found. 3 .



Gambar 3. Activity diagram olah data admin

b) Activity Diagram Guru olah data guru 
Berikut adalah gambar activity diagram bagian guru yang dimana ada pengolahan data siswa, input nilai dan lain sebagainya dapat dilihat pada Error! Reference source not found. 4 .

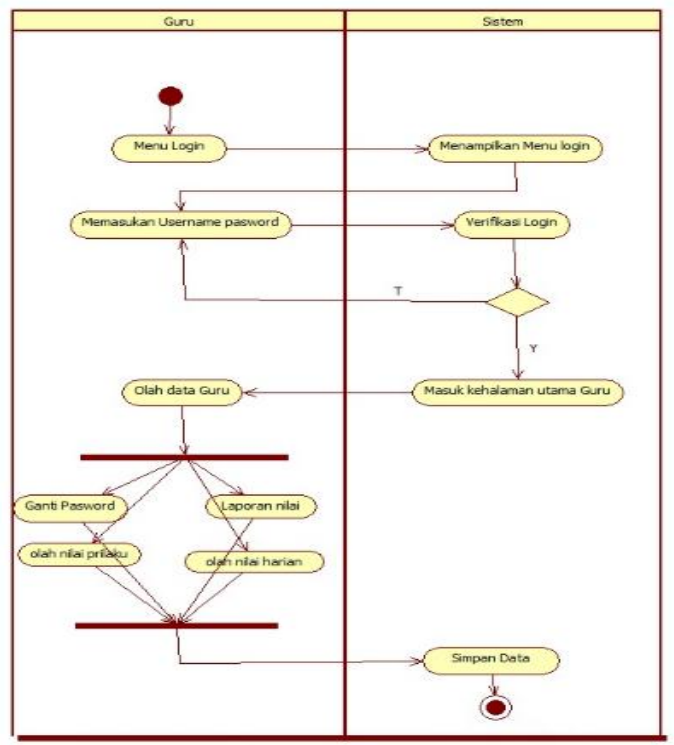

Gambar 4. activity diagram bagian Guru

\section{c) Activity Diagram Siswa olah data Siswa}

Berikut adalah activity diagram bagian siswa, siswa dapat login dan melihat nilai dan informasi yang ada di sekolah dari hasil belajarnya dapat dilihat pada Error! Reference source not found.5.

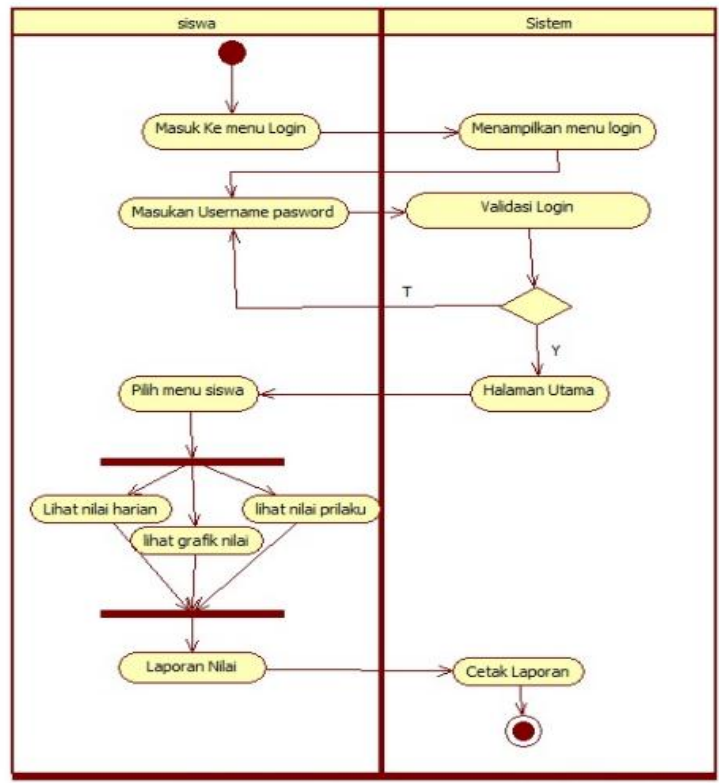

Gambar 5. Activity diagram Siswa

\section{d) Class Diagram}

Class Diagram adalah diagram yang menunjukan classclass yang ada dari sebuah sistem dan saling berhubungan secara logika (Roger S. Pressman, 2012: ) Berikut adalah class diagram pada sekolah dapat dilihat pada Error! Reference source not found. 6 .



Gambar 6. Class Diagram

\section{Squence Diagram}

Berikut ini adalah alur dari aktifitas admin untuk mengolah data admin yang dapat menghapus melihat dan mengolah data admin dapat dilihat pada Error! Reference source not found. 7 .

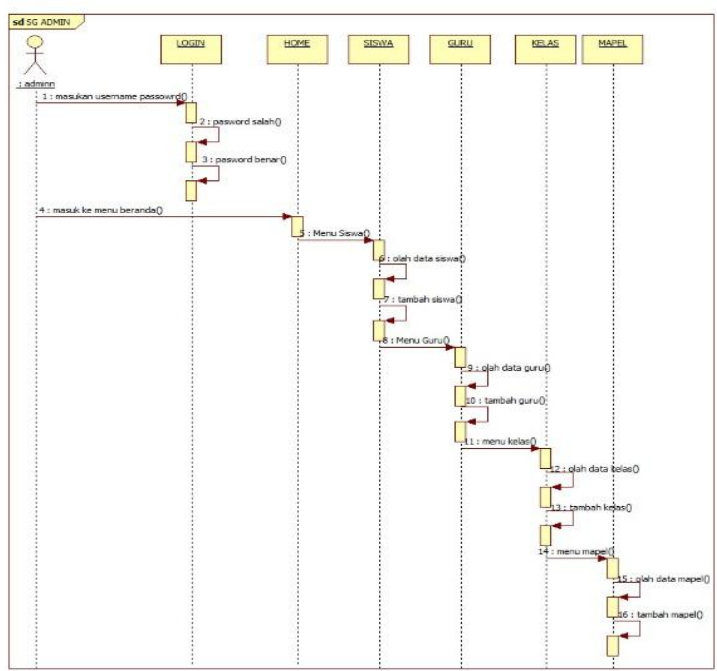

Gambar 7. Sequence Diagram Admin

\section{HASIL DAN PEMBAHASAN}

\subsection{Hasil Analisa Laporan}

Hasil penelitian ini yaitu mengimplementasikan sistem agar sistem dapat dioperasikan. Setelah melakukan analisa, desain dan pengkodean menggunakan bahasapemrograman $P H P$ didukung database $M y S Q L$, maka sistem yang sudah jadi akan digunakan oleh bagian Admin danguru, namun sebelum di gunakan oleh siswa dan orang tua sistem harus di lakukan testing terlebih dahulu, hal ini dimaksudkan apakah sistem berjalan dengan baik sehingga tujuan pembuatan sistem berguna dalam penyebaran informasi ini dapat tercapai.

\subsection{Pembahasan dan Penelitian}

Sistem yang telah dianalisis dan didesain secara rinci dan telah diseleksi, selanjutnya sistem dapat diimplementasikan (diterapkan).Tahap implementasi sistem merupakan tahap dimana sistem siap untuk 
dioperasikan.Tahap ini juga termasuk dalam kegiatan melakukan pengkodean program.

\subsection{Teknik Pengujian Perangkat Lunak Kotak Hitam}

Pengujian kotak hitam atau biasa disebut dengan Black-box Testing merupakan pendekatan dalam teknik pengujian kualitas menggunakan kuesioner. Kriteria pemilihan karakteristik responden sebagai sampel penelitian untuk pengujian kualitas perangkat lunak ini berdasarkan tingkat pengguna yang akan mengakses sistem yang dibuat. Responden tersebut yaitu guru dan wali murid seperti bagian lihat nilai, laporan nilai, nilai prilaku pada sekolahan SMA N 1 Kalirejo tersebut.

Hasil identifikasi ISO 9126, dari enam karakteristik kualitas sebuah aplikasi ditetapkan hanya empat karakteristik saja yang dijadikan variabel dalam penelitian ini, yaitu functionality, reliability, usability, dan efficiency. Dua karakteristik lainnya yaitu maintainability dan portability tidak menjadi fokus penelitian. Berikut adalah kisi - kisi pengukuran kualitas perangkat lunak dan indikator yang akan digunakan untuk kuesioner dalam black box testing dapat dilihat pada tabel 1 di bawah ini.

Tabel 1. Kisi-kisi Pengukuran Kualitas Aplikasi

\begin{tabular}{|c|c|c|c|}
\hline Variabel & $\begin{array}{l}\text { Sub- } \\
\text { variabel }\end{array}$ & Indikator Pengukuran & $\begin{array}{l}\text { No. } \\
\text { Butir } \\
\text { Uji }\end{array}$ \\
\hline \multirow[t]{5}{*}{ Functionality } & Suitability & $\begin{array}{l}\text { Kesesuaian sistem } \\
\text { dengan kebutuhan }\end{array}$ & 1,2 \\
\hline & Accuracy & $\begin{array}{l}\text { Keakuratan informasi } \\
\text { yang dihasilkan oleh } \\
\text { system }\end{array}$ & 3,4 \\
\hline & Security & $\begin{array}{l}\text { Keamanan data dan } \\
\text { pengguna }\end{array}$ & 5,6 \\
\hline & $\begin{array}{l}\text { Interoperabi } \\
\text { lity }\end{array}$ & $\begin{array}{l}\text { Integritas dan akses } \\
\text { sistem } \\
\text { perbedaan dengan } \\
\text { yang digunakan }\end{array}$ & 7,8 \\
\hline & Compliance & $\begin{array}{l}\text { Kesesuaian sistem } \\
\text { dengan peraturan yang } \\
\text { berlaku }\end{array}$ & 9 \\
\hline \multirow[t]{3}{*}{ Reliability } & Maturity & $\begin{array}{l}\text { Rendahnyatingkat } \\
\text { kesalahan dalam sistem }\end{array}$ & 10,11 \\
\hline & $\begin{array}{l}\text { Fault } \\
\text { tolerance }\end{array}$ & $\begin{array}{l}\text { Kemampuan untuk } \\
\text { berfungsi seperti biasa } \\
\text { setelah terjadi kesalahan }\end{array}$ & 12,13 \\
\hline & $\begin{array}{l}\text { Recoverabil } \\
\text { ity }\end{array}$ & \begin{tabular}{l} 
Kemampuan \\
\multicolumn{2}{c}{ sistem } \\
untuk \\
mengatasi $\quad$ kesalahan \\
yang terjadi
\end{tabular} & 14 \\
\hline \multirow[t]{4}{*}{ Usability } & $\begin{array}{l}\text { Understandi } \\
\text { bility }\end{array}$ & $\begin{array}{ll}\text { Kemudahan } & \text { sistem } \\
\text { untuk dipahami } & \\
\end{array}$ & 15,16 \\
\hline & Learnability & $\begin{array}{ll}\text { Kemudahan } & \text { sistem } \\
\text { untuk dipelajari } & \\
\end{array}$ & 17,18 \\
\hline & Operability & $\begin{array}{l}\text { Kemudahan sistem } \\
\text { untuk dioperasikan }\end{array}$ & 19,20 \\
\hline & $\begin{array}{l}\text { Attractivene } \\
\text { ss }\end{array}$ & $\begin{array}{l}\text { Kenyamananpengguna } \\
\text { dalam menggunakan } \\
\text { system }\end{array}$ & 21,22 \\
\hline \multirow[t]{2}{*}{ Efficiency } & $\begin{array}{l}\text { Time } \\
\text { behavior }\end{array}$ & $\begin{array}{l}\text { Kecepatan respon dan } \\
\text { waktu pengolahan }\end{array}$ & 23,24 \\
\hline & $\begin{array}{l}\text { Resource } \\
\text { behavior }\end{array}$ & $\begin{array}{l}\text { Kesesuaian penggunaan } \\
\text { sumber daya }\end{array}$ & 25 \\
\hline
\end{tabular}

\subsection{Tabel Kuisioner Responden SMA N 1 Kalirejo}

Sampel Kuisioner yang disebarkan terkait Perancangan Monitoring prestasi akademik dan aktifitas siswa Pada SMA N 1 Kalirejo adalah guru, pegawai dan siswa pada SMA Negeri 1 Kalirejo. Jumlah responden untuk pengujian system ini yaitu berjumlah 20 respoden, berikut ini adalah table responden yang dapat dilihat pada tabel 2. berikut ini :

Tabel 2. Hasil Pengujian Responden atau angket Kuisioner

\begin{tabular}{|c|c|c|c|c|}
\hline 1 & $\begin{array}{lllr}\text { Apakah } & \text { system } & \text { ini } \\
\text { berguna } & & \text { untuk } \\
\text { sekolahan } & \text { SMa } & \text { N } & 1 \\
\text { Kalirejo ? } & & & \\
\end{array}$ & 15 & 3 & 2 \\
\hline 2 & 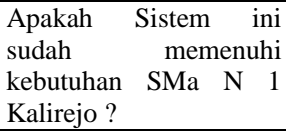 & 18 & 2 & 0 \\
\hline 3 & $\begin{array}{l}\text { Apakah kinerja system } \\
\text { ini sudah berjalan } \\
\text { dengan baik? }\end{array}$ & '17 & 3 & 0 \\
\hline 4 & $\begin{array}{l}\text { Apakah system mudah } \\
\text { digunakan oleh } \\
\text { penggunaatau user? }\end{array}$ & 16 & 2 & 2 \\
\hline 5 & $\begin{array}{l}\text { Apakah data yang } \\
\text { ditampilkan sudah falid } \\
\text { ? }\end{array}$ & 20 & 0 & 0 \\
\hline 6 & $\begin{array}{l}\text { Apakah system dapat } \\
\text { memonitoring nilai dari } \\
\text { peserta didik SMa N } 1 \\
\text { Kalirejo? }\end{array}$ & 18 & 2 & 0 \\
\hline
\end{tabular}

\subsection{Kesimpulan Hasil pengujian Validasi.}

Berdasarkan hasil Responden diatas, maka dapat disimpulkan bahwa system monitoring prestasi akademik dan aktifitas siswa tersebut sudah sesuai dengan spesifikasi kebutuhan fungsional yang dibutuhkan pengguna. Dengan demikian berdasarkan hasil analisis, perancangan dan kontruksi perangkat lunak untuk pengembangan perancangan monitoring prestasi akademik dan aktifitas siswamenggunakan metode pengembangan sistem informasi model waterfall dapat berfungsi menyediakan database serta mendukung kecepatan layanan informasi pengawasan.

\subsection{Hasil Pengolahan Data}

Data diperoleh dengan cara membagikan kuesioner kepada 20 responden dari siswa guru dan orang tua tentang system yang sedang dibangun dengan 25 pertanyaan.

Tabel 3. Hasil Perhitungan ISO 9126 Perancangan Monitoring Prestasi Akademik dan Aktifitas Siswa SMA N 1 Kalirejo.

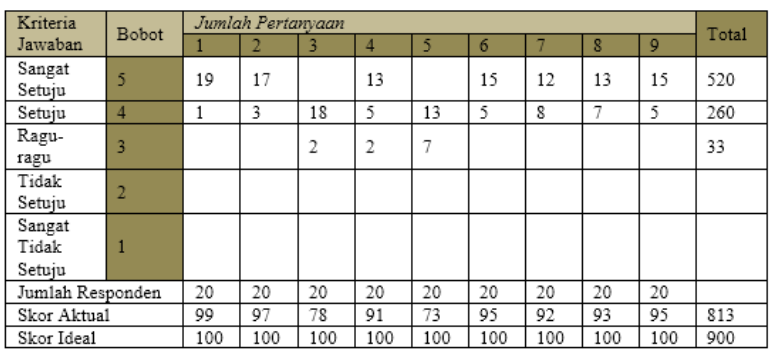


$\%$ Skor Aktual $=\frac{\text { Skor Aktual }}{\text { Skor Ideal }} \times 100 \%$

$$
=\frac{831}{900} \times 100 \%=92,3 \% \quad(\text { Kriteria }
$$

Sangat Baik)

Berdasarkan perhitungan diatas dapat disimpulkan bahwa tingkat Sistem perancangan monitoring prestasi akademik dan aktifitas siswa dengan pendekatan key performance indicator dalam aspek Functionality yang diberikan yaitu sangat baik dengan angka nilai 92,3\%.

Tabel 4. Hasil Perhitungan ISO 9126 Perancangan Monitoring Prestasi Akademik dan Aktifitas Siswa SMA N 1 Kalirejo.

\begin{tabular}{|c|c|c|c|c|c|c|c|}
\hline \multirow{2}{*}{$\begin{array}{l}\text { Kriteria } \\
\text { Jawaban }\end{array}$} & \multirow{2}{*}{ Bobot } & \multicolumn{5}{|c|}{ Jumlah Pertanyaan } & \multirow[b]{2}{*}{ Total } \\
\hline & & 1 & 2 & 3 & 4 & 5 & \\
\hline $\begin{array}{l}\text { Sangat } \\
\text { Setuju }\end{array}$ & 5 & 13 & & & 12 & & 125 \\
\hline Setuju & 4 & 7 & 17 & 16 & 8 & 18 & 264 \\
\hline Ragu-ragu & 3 & & 3 & 4 & & 2 & 27 \\
\hline $\begin{array}{l}\text { Tidak } \\
\text { Setuju }\end{array}$ & 2 & & & & & & \\
\hline \multicolumn{8}{|l|}{$\begin{array}{l}\text { Sangat } \\
\text { Tidak } \\
\text { Setuju }\end{array}$} \\
\hline \multicolumn{2}{|c|}{ Jumlah Responden } & 20 & 20 & 20 & 20 & 20 & \\
\hline \multicolumn{2}{|l|}{ Skor Aktual } & 93 & 77 & 76 & 92 & 78 & 416 \\
\hline \multicolumn{2}{|l|}{ Skor Ideal } & 100 & 100 & 100 & 100 & 100 & 500 \\
\hline
\end{tabular}

$\%$ Skor Aktual $=\frac{\text { Skor } \text { Aktual }}{\text { Skor Ideal }} \times 100 \%$

$$
\begin{aligned}
& =\frac{416}{500} \mathrm{x} 100 \% \\
& =83,2 \% \text { (Kriteria Baik) }
\end{aligned}
$$

Berdasarkan perhitungan diatas dapat disimpulkan bahwa tingkat Sistem perancangan monitoring prestasi akademik dan aktifitas siswa dengan pendekatan key performance indicator dalam aspek Reliability yang diberikan yaitu baik dengan angka nilai $83,2 \%$.

Tabel 5. Hasil Perhitungan ISO 9126 Perancangan Monitoring Prestasi Akademik dan Aktifitas Siswa SMA N 1 Kalirejo Dalam Aspek Usability

\begin{tabular}{|l|l|l|l|l|l|l|l|l|l|l|}
\hline $\begin{array}{l}\text { Kriteria } \\
\text { Jawaban }\end{array}$ & \multirow{2}{*}{ Bobot } & \multicolumn{7}{|c|}{ Jumlah Pertanyaan } & Total \\
\hline & 1 & 2 & 3 & 4 & 5 & 6 & 7 & 8 & \\
\hline $\begin{array}{l}\text { Sangat } \\
\text { Setuju }\end{array}$ & 5 & 17 & 16 & 7 & 3 & 16 & 6 & 16 & 18 & 495 \\
\hline Setuju & 4 & 3 & 4 & 13 & 14 & 4 & 13 & 4 & 2 & 228 \\
\hline $\begin{array}{l}\text { Ragu- } \\
\text { ragu }\end{array}$ & 3 & & & & 3 & & 1 & & & 12 \\
\hline $\begin{array}{l}\text { Tidak } \\
\text { Setuju }\end{array}$ & 2 & & & & & & & & & \\
\hline $\begin{array}{l}\text { Sangat } \\
\text { Tidak } \\
\text { Setuju }\end{array}$ & 1 & & & & & & & & & \\
\hline $\begin{array}{l}\text { Jumlah } \\
\text { Responden }\end{array}$ & 20 & 20 & 20 & 20 & 20 & 20 & 20 & 20 & \\
\hline Skor Aktual & 97 & 96 & 87 & 80 & 96 & 85 & 96 & 98 & 735 \\
\hline Skor Ideal & 100 & 100 & 100 & 100 & 100 & 100 & 100 & 100 & 800 \\
\hline
\end{tabular}

$$
\begin{aligned}
\% \text { Skor Aktual }= & \frac{\text { Skor Aktual }}{\text { Skor Ideal }} \times 100 \% \\
& =\frac{735}{800} \times 100 \% \\
& =91,9 \% \text { (Sangat Baik) }
\end{aligned}
$$

Berdasarkan perhitungan diatas dapat disimpulkan bahwa tingkat Sistem perancangan monitoring prestasi akademik dan aktifitas siswa dengan pendekatan key performance indicator dalam aspek Usability yang diberikan yaitu sangat baik dengan angka nilai $91,9 \%$.
Tabel 6. Hasil Perhitungan ISO 9126 Perancangan Monitoring Prestasi Akademik dan Aktifitas Siswa SMA N 1 Kalirejo Aspek Efficiency

\begin{tabular}{|l|l|l|l|l|l|}
\hline $\begin{array}{l}\text { Kriteria } \\
\text { Jawaban }\end{array}$ & \multirow{2}{*}{ Bobot } & \multicolumn{3}{|l|}{ Jumlah Pertanyaan } & \multirow{2}{*}{ Total } \\
\cline { 3 - 6 } & & 1 & 2 & 3 & 50 \\
\hline $\begin{array}{l}\text { Sangat } \\
\text { Setuju }\end{array}$ & 5 & 7 & 2 & 1 & 52 \\
\hline Setuju & 4 & 13 & 13 & 12 & 152 \\
\hline Ragu-ragu & 3 & & 5 & 7 & 36 \\
\hline $\begin{array}{l}\text { Tidak } \\
\text { Setuju }\end{array}$ & 2 & & & & \\
\hline $\begin{array}{l}\text { Sangat } \\
\text { Tidak } \\
\text { Setuju }\end{array}$ & 1 & & & & \\
\hline \multicolumn{2}{|l|}{ Jumlah Responden } & 20 & 20 & 20 & \\
\hline \multicolumn{2}{|l|}{ Skor Aktual } & 87 & 77 & 74 & 238 \\
\hline \multicolumn{2}{|l|}{ Skor Ideal } & 100 & 100 & 100 & 300 \\
\hline
\end{tabular}

$$
\begin{aligned}
\% \text { Skor Aktual }= & \frac{\text { Skor Aktual }}{\text { Skor Ideal }} \times 100 \% \\
& =\frac{238}{300} \times 100 \% \\
& =79,3 \% \text { (baik) }
\end{aligned}
$$

Berdasarkan perhitungan diatas dapat disimpulkan bahwa tingkat Sistem perancangan monitoring prestasi akademik dan aktifitas siswa dengan pendekatan key performance indicator dalam aspek Efficiency yang diberikan yaitu baik dengan angka nilai 79,3\%

Karena pengembangan diukur dalam jam, hari, minggu dan bulan maka kesalahan perkiraan (estimation error) yang dibutuhkan untuk perancangan dan implementasi menjadi kecil.

\section{KESIMPULAN DAN SARAN}

\subsection{Kesimpulan}

Berdasarkan Pembahasan diatas dapat disimpulkan :

1) Perancangan Monitoring prestasi akademik dan aktifitas siswa menggunakan pendekatan key performance indicator pada SMA N 1 Kalirejo menggunakan Tools StarUML (Unified Modelling Language) : Usecase Diagram,Activity Diagram, Class Diagram, dan Sequence Diagram dan pengujian system menggunakan ISO 9126.

2) Perancangan Monitoring prestasi akademik dan aktifitas siswa menggunakan pendekatan key performance indicator dapat memudahkan pengguna melakukan pengawasan terhadap nilai atau prestasi siswa dan mempermudah menyimpan data-data jika terjadi sesuatu yang tidak diinginkan oleh sekolah.

3) Pengujian sistem yang dibangun menggunakan pengujian ISO 9126 dengan metode kuisioner yang berhubungan dengan functionality (fungsionalitas), reliability (kehandalan), usability (kebergunaan), dan effesiency (efesiensi), Adapun hasil pengujiannya dengan menggunakan ISO 9126 yaitu : 

a. dalam aspek Functionality yang diberikan yaitu sangat baik dengan angka nilai $92,3 \%$.
b. dalam aspek Reliability yang diberikan yaitu baik dengan angka nilai 83,2\%.
c. dalam aspek Usability yang diberikan yaitu sangat baik dengan angka nilai 91,9\%.
d. dalam aspek Efficiency yang diberikan yaitu baik dengan angka nilai 79,3\%

\subsection{Saran}

Berdasarkan kesimpulan diatas penulis memberikan saran : Perancangan Monitroing prestasi akademik dan aktifitas siswa menggunakan key performance indicator dapat mempermudah pekerjaan penggunanya dan dapat diimplimentasikan dikehidupan nyata.
Dan diharapkan dapat berkembang lagi untuk penelitian selanjutnya, agar bisa lebih baik lagi dari yang saya rancang.

\section{DAFTAR PUSTAKA}

Nasution, S. (1987). Berbagai Pendekatan dalam Proses Belajar Mengajar. Jakarta: Bina Aksara

Poerwanto, Ngalim. (2007). Psikologi Pendidikan. Bandung: PT Rosda Karya

Pressman, Roger, 2012, Rekayasa Perangkat Lunak, Yogyakarta : ANDI.

Sawiji, 2008. SistemInformasi Monitoring. Yogyakarta: ANDI.

Winkel WS. (1997). Psikologi Pendidikan dan Evaluasi Belajar. Jakarta: Gramedia. 